\title{
Industry practice training through modular classroom exercises
}

\section{Dr. Arthur Felse, Northwestern University}

Dr. P. Arthur Felse is a lecturer in the Master of Biotechnology Program and the Department of Chemical and Biological Engineering at Northwestern University. His responsibilities include teaching, student advising, coordinating masters students' research training, and managing the biotechnology teaching laboratory. Before joining Northwestern University, Dr. Felse completed his post-doctoral training at the Polytechnic Institute of New York University where he received the EPA's Presidential Green Chemistry Challenge Award for his work on mild and selective polymerizations using lipases. Dr. Felse served as a faculty in the 2012 Chemical Engineering Summer School. 


\title{
Industry practice training through modular classroom exercises
}

\begin{abstract}
This poster describes a set of modular exercises that were developed to provide students with training in two areas of industrial relevance, viz., regulatory compliance (RC) and safety compliance (SC). The modules included training in written communication skills that are required to prepare compliance documentation. The overall goal of these modules is to create an awareness and exposure among engineering students to industry practices. Exercises these modules give students a hands-on experience in implementing regulatory and safety guidelines, while understanding their importance as well as the rigor involved in implementing them. Modules described in this poster can be implemented in lab, lecture or design courses.
\end{abstract}

\section{Introduction}

For today's engineers, superior technical knowledge is not sufficient for success. Instead, engineers now regularly work in cross functional teams that include non-technical disciplines such as management, regulatory affairs, and finance ${ }^{1}$. Thus, successful engineering practice requires functional knowledge in the areas regulatory affairs, and safety which are becoming mainstream capabilities for engineers. To meet the demands for a rapidly changing, technologydriven workforce, the industry and educational advisory bodies have recommended that academic instruction should include industry practice training ${ }^{2}$. Many programs and universities have accomplished industry practice training through co-operative education, industry fellows programs, guest lectures, capstone projects, courses co-taught with the industry, and field trips ${ }^{3,4}$.

This poster describes an effort to translate some industry practices into classroom education. Experiential laboratory, design projects, classroom lectures or seminars can be used to include industry practice exercises. The essence of this work is to develop short modules that can be included in many courses rather than a standalone course in industry practice. Engineering practice in the industry is a culture in itself ${ }^{5}$. Thus industry practice instruction should focus on effecting a cultural or habitual change in students' approach to engineering profession. Modules presented here intend to frequently expose students to industry practice challenges. This poster discusses development of modules for instruction in two key areas of industry practice, namely (i) regulatory compliance, (ii) safety compliance. Strategies to provide hands-on training in these industry practice areas by way of including them in theory and laboratory courses is discussed. These modules were developed and updated through constant input from collaborators in the industry. Student opinions and recommendations for future are presented. 


\section{Learning objectives of the industry practice module}

The overall, broad objective of the industry practice modules is to expose students to some aspects of regulatory and safety compliance, and to train them to be at a level where they can successfully liaison with professionals involved in regulatory and safety compliance. These modules are designed to give students a better understanding and appreciation for regulatory and safety procedures implemented in the industry.

When the modules are completed, students should:

1. Have a working knowledge on regulatory compliance through good laboratory practices training.

2. Have a working knowledge on safety compliance, risk assessment, and hazard mitigation in a laboratory environment.

3. Understand the risks of regulatory and safety non-compliance.

4. Have functional knowledge to work with professionals in RC and SC areas.

5. Have the ability to write and understand RC and SC documentation.

6. Understand the interplay between technical aspects and compliance aspects of $\mathrm{CHE}$ profession.

\section{General teaching methodology}

$\mathrm{RC}$ and SC modules are designed to be used in lecture, laboratory or design courses. All instruction in these modules was done through a project-based approach with the instructor taking the role of a coach rather than a teacher. The instructor chaperoned brainstorming sessions, coached students on RC documentation, and monitored role-play exercises. A learningby-doing education model was adopted, i.e., no formal instruction was provided. Required reading materials were provided to students for self study. The instructor broadly supervised and advised student groups. Grades were assigned based on instructor's observation of student work. It is important to note that grades for these modules are not entirely quantifiable at the moment, and hence an element of subjectivity will exist in grading. To circumvent this problem, modules are currently graded as a pass/no-pass component of the course in which they are offered. In future, a grading rubric will be developed to assign a quantifiable number or letter grades for student work in RC and SC modules.

All work in RC and SC modules was done in teams. A clear emphasis was placed on collective learning practices ${ }^{6}$, i.e., students learnt from each other and from the instructor as they moved forward with their projects. Several cognitive studies have shown that humans quickly learn habits from their immediate environment and that their collective interaction with the community enhances learning ${ }^{7}$. Observations from teaching this module support this opinion students by way of participating in group activities immediately emulated practices in the environment that surround them. Hence it is important for the instructor to provide an environment or community where RC and SC are taken seriously with as much intensity as that 
of a core course topic. Instructional materials were developed in conjugation with professionals in the industry and exercises closely mimicked industry procedures. Guest lectures by industry professionals were included to give students a first-hand exposure to industry practices and to discuss their work (one each on RC and SC). Teaching methodologies used in RC and SC modules are described in their respective sections.

\section{Regulatory compliance module}

Regulatory compliance has been and will increasingly be a key component in successful operation of chemical and related industries. A Chemical Week survey in 2010 of major chemical and related companies indicated that $75 \%$ have reorganized their development efforts to meet current regulatory compliance needs ${ }^{8}$. The same survey also indicated that less than a third of the companies will be compliant by 2010. Based on this and other reports CNN Money predicts that regulatory compliance will be a major factor in the competitive advantage of chemical industries in future ${ }^{9}$.

As many chemical companies move towards complete compliance, an increasing need for professionals with RC awareness is to be expected. Also, the need for RC-aware chemical engineers will further increase as more and more migrate to highly regulated industries such as electronics, food, pharmaceuticals and biotechnology. Employment of chemical engineers in four most regulated industries is shown in figure 1. It is evident that more than two-thirds of chemical engineers will work in a strictly regulated environment. Hence it is important for universities to provide some exposure to RC and also cultivate a culture of compliance among CHE students.

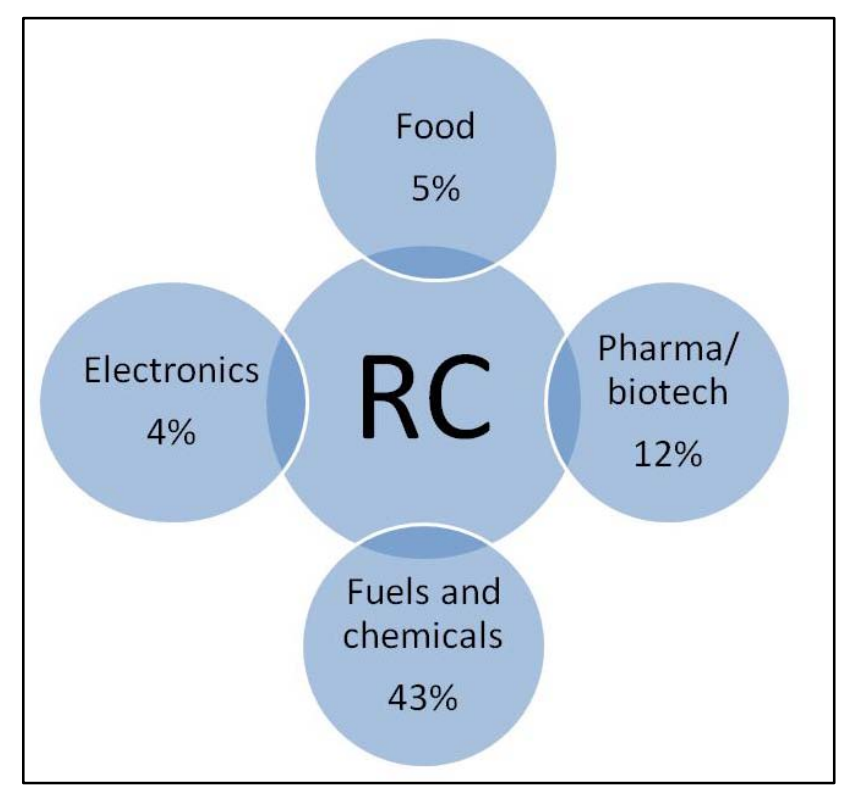

Figure 1. Employment of chemical engineers in strictly regulated industries as of 2007. Adapted from ref \#10. 
Regulatory compliance has now become a matter of consumer confidence and the economy associated with it. A presidential executive order in early 2011 required greater transparency of RC related activities of enforcing agencies such as FDA and EPA (figure 2). Due to this executive order regulatory violations and corrective actions will available to the public and consequently all potential customers in the form of a searchable electronic database. Thus, there is a higher burden on the chemical industry to become compliant, which is possible only through a RC-trained workforce.

For Immediate Release, January 18, 2011

Presidential Memoranda - Regulatory Compliance MEMORANDUM FOR THE HEADS OF EXECUTIVE DEPARTMENTS AND AGENCIES SUBJECT: Regulatory Compliance

“......and to make readily accessible to the public, information concerning their regulatory compliance and enforcement activities, such as information with respect to administrative inspections, examinations, reviews, warnings, citations, and revocations......."

"Greater disclosure of regulatory compliance information fosters fair and consistent enforcement of important regulatory obligations. ....."

"Sound regulatory enforcement promotes the welfare of Americans in many ways, by increasing public safety, improving working conditions, and protecting the air we breathe and the water we drink. ....."

Figure 2. Excerpts from the presidential memoranda requiring all regulatory information to be made public ${ }^{11}$.

Purpose of the RC module

Regulatory compliance was taught using Good Laboratory Practice (GLP) as an example. In practicum GLP training was provided through a module in our bioprocess engineering laboratory course. This work started a few years ago and the first efforts were reported in a previous ASEE Conference ${ }^{12}$. Students were exposed to FDA regulations related to GLP, common compliance practices, enforcement, and consequences of non-compliance. This module intends to: (i) Develop a understating of the letter and spirit of GLP regulations, (ii) develop a working knowledge of GLP, and (iii) develop a familiarity with GLP documentation.

GLP is a set of federally mandated guidelines under which experiments are planned, conducted, monitored, recorded and reported. It intends to promote quality, traceability, and integrity of scientific data. GLP is enforced by regulating agencies such as FDA and EPA, and each have their own regulations. FDA and EPA derive their enforcement authority from federal acts of the United States Congress and are codified in the Code of Federal Regulation (CFR). Each enforcement agency has its own Title Number - 21 for FDA and 40 for EPA (figure 3). In this module, training was provided on FDA's 21 CFR Part 58 relating to Good Laboratory Practices for Nonclinical Studies. A related regulation is EPA's 40 CFR Part 160 relating to Good Laboratory Practice Standards. 


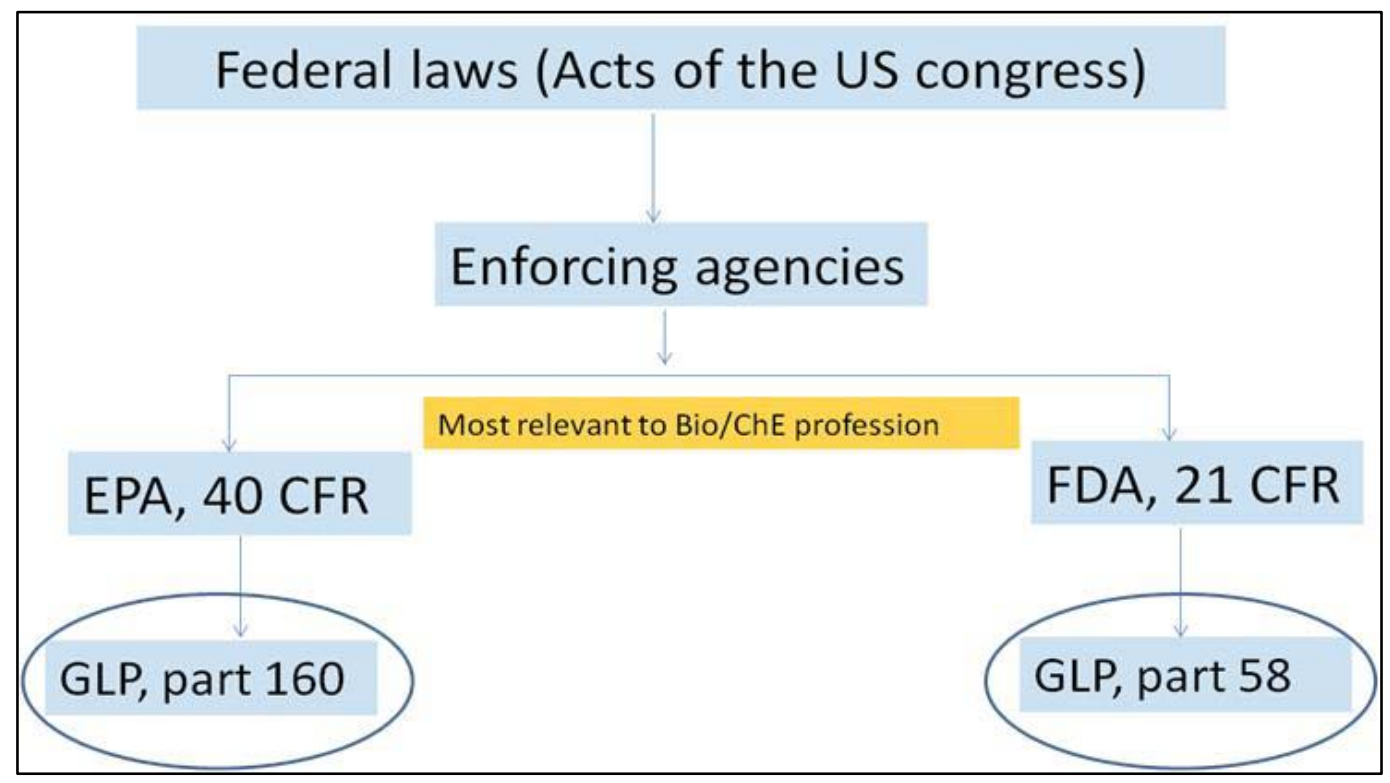

Figure 3. Regulatory agencies relevant to CHE and BioCHE professions. GLP regulations that relate to FDA 21 CFR Part 58 were used in the RC module.

\section{Topics covered in the RC module}

The RC module is designed to be implemented in a laboratory or a lecture course. However, an experiment should be done to generate a batch record. Form 483 can be generated through mock audit of a functioning lab using simulated SOP and batch record. SOP can be generated as a classroom or homework exercise. Benefits of the RC module can be fully realized in a laboratory experiment, but a classroom exercise will give sufficient exposure. Topics covered in this module include:

1. GLP guidelines for conduct of lab experiments as required by 21 CFR Part 58

2. Setting-up a GLP compliant laboratory

3. Conducting a GLP-like experiment

4. Mock inspection of a GLP compliant facility, and

5. Writing GLP documentation such as standard operating procedure (SOP), batch record and inspection observational report (FDA form 483).

\section{$\underline{\text { Regulatory compliance instruction }}$}

Instruction for the RC module started with a lecture on the history and overview of regulatory compliance with some information on regulatory agencies. This lecture was followed by assigning study materials and a brief multiple choice quiz. The relevance of regulatory 
compliance and its impact on chemical engineering profession were demonstrated through student-led case study discussions which included real non-compliance citations.

The whole class then brainstormed ideas to transform an academic teaching laboratory in to a GLP-compliant facility. Regulations from FDA's 21CFR Part 58 were used as a guideline for this. Sections of 21CFR Part 58 relevant to this RC module are given in Appendix 1 (see subpart $\mathrm{C}$ for facilities). The class then generated a list of changes that needed to be made to make the lab GLP-compliant. The checklist included changes to the facility, operational changes, and logistics changes. All possible changes were implemented before performing a GLP experiment. It should be noted that not all changes can be implemented due to infrastructure/economic limitations. A typical checklist is given in table 1.

Table 1. Representative checklist of modifications to convert a teaching laboratory into a GLPcompliant facility.

\begin{tabular}{|c|c|c|}
\hline Facility modifications & Operational modifications & Logistics modifications \\
\hline $\begin{array}{l}\text { 1. Separate work stations to } \\
\text { avoid cross-contamination. } \\
\text { 2. Clearly mark traffic routes } \\
\text { in the aisles between work } \\
\text { benches for personnel and } \\
\text { carts. } \\
\text { 3. Create secure space for } \\
\text { GLP document archives. } \\
\text { 4. Create secure space for } \\
\text { sample storage. } \\
\text { 5. Label all equipments. }\end{array}$ & $\begin{array}{l}\text { 1. Make sure maintenance and } \\
\text { calibration records for all } \\
\text { equipments are available. } \\
\text { 2. Use only supplies that have } \\
\text { traceable batch numbers. } \\
\text { 3. Generate a log book for all } \\
\text { GLP documents and assign } \\
\text { retrievable IDs for each. } \\
\text { 4. Label and date all reagents } \\
\text { prepared in the lab. } \\
\text { 5. Establish disposal and } \\
\text { cleaning procedures. }\end{array}$ & $\begin{array}{l}\text { 1. Develop an electronic database } \\
\text { to track the flow chemicals and } \\
\text { supplies within the lab. } \\
\text { 2. Develop a GLP organizational } \\
\text { structure and assign roles for } \\
\text { each team members. } \\
\text { 3. Develop a flow chart for the } \\
\text { sequence of signatures that are } \\
\text { to be obtained in GLP } \\
\text { documentation. } \\
\text { 4. Develop and post guidelines } \\
\text { for conduct of individuals not } \\
\text { working in the lab. }\end{array}$ \\
\hline
\end{tabular}

In the second brainstorm session which involved individual teams, ideas were discussed to modify an existing experimental protocol to make it GLP-compliant. Regulations from FDA's 21CFR Part 58, subpart G was used as a guideline (Appendix 1). Student teams generated a GLP-compliant protocol, also called Standard Operating Procedure (SOP). SOP needs to be descriptive to an extent that the person using it should be able to do the experiment correctly without consulting the author. SOPs were evaluated during a mock audit. Two example experiments for generating SOP are given in Table 2. It will be best if students have some prior knowledge on these experiments. Any experiment that students have done in a current or previous lab course can be used to generate SOP. It is common practice in the industry to generate SOPs using a template. A SOP template was developed by the instructor with help from professionals in the pharmaceutical industry. This template, shown in Appendix 2 was given to students to help generate their SOPs. 
Table 2. Example GLP experiments for generation of SOP and batch record.

1. Generating a standard curve for protein estimation.

You are given a protein solution with of $\mathrm{X}$ mg protein/ml in RO water. Dilute it 1:1, 1:2, 1:5, 1:10, 1:20, 1:50, and 1:100. Measure absorbance of each of dilution at $280 \mathrm{~nm}$. Plot a straight line graph of protein concentration vs. absorbance and report the linear equation and $\mathrm{R}^{2}$ value.

Note: Absorbance readings below .01 and above 1.0 are not reliable. Absorbance measurements require a special cuvette.

2. Prepare cell growth media and measure its $\mathrm{pH}$ and optical density at $600 \mathrm{~nm}$.

You are asked to prepare 2L of four different media for bacterial cell growth. Composition is: Glucose = $5 \mathrm{~g} / \mathrm{L}$, yeast extract $=5.0 \mathrm{~g} / \mathrm{L}$, mineral salt $\operatorname{mix}=2.0,5.0,10.0$, and $20.0 \mathrm{~g} / \mathrm{L}$. Prepare these media and report its $\mathrm{OD}_{600}$ and $\mathrm{pH}$.

Student teams conducted the GLP experiment according to the SOP they had generated and recorded data in a batch record. Batch record is a key regulatory evidence to demonstrate that an experiment was actually performed and the accompanying data was obtained. Like SOP, batch record templates were provided to students. Example of a batch record template is given in Appendix 3. GLP documents were generated and reviewed according to the GLP organization structure given in figure 4. Students played the roles of Associate, Study Director and Quality Assurance Unit in a GLP environment and signed off on appropriate documents. Students assumed responsibilities for their roles as described in 21 CFR Part 58, sections 33 and 35 (Appendix 1) during experiments and during mock audit.

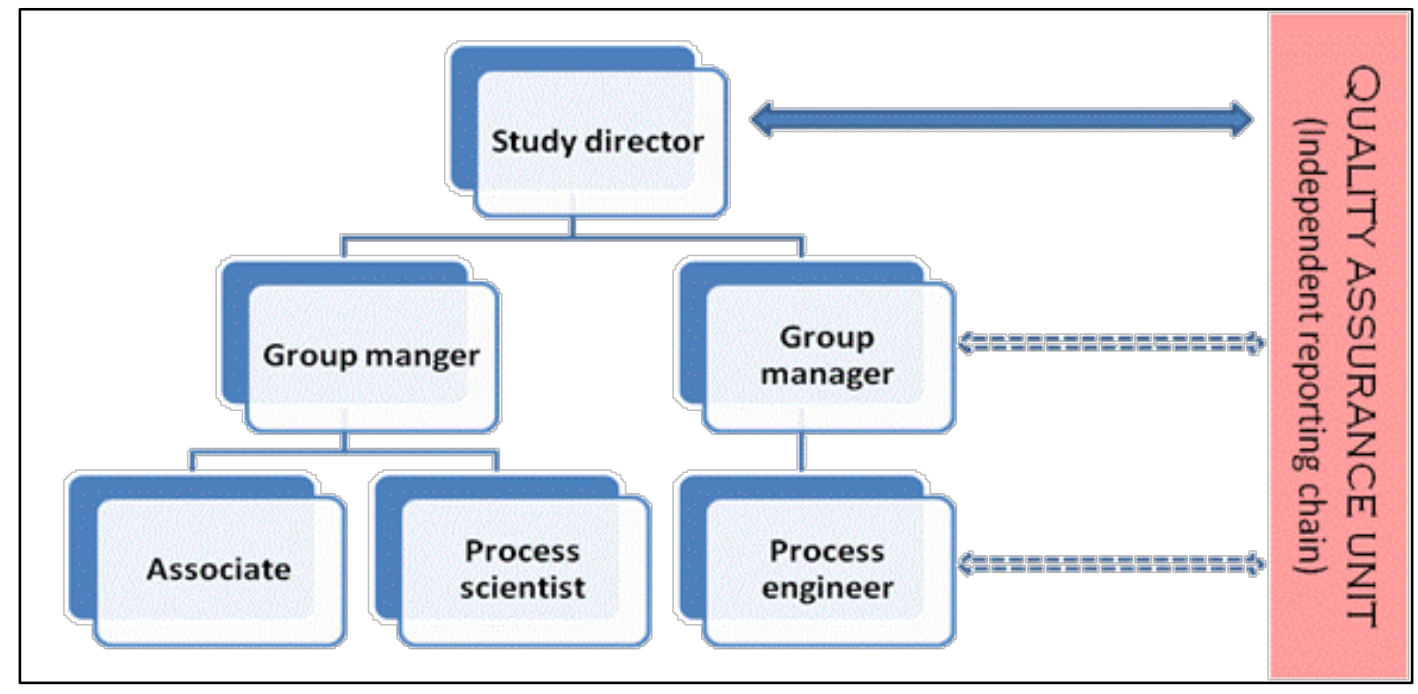

Figure 4. GLP organizational structure.

Last part of the GLP module was a mock inspection by student teams which were randomly assigned to audit other teams. The audit included inspection of facilities, examination of SOP and batch records, and interview with personnel as per the organizational structure given 
in figure 4. Students playing the role of quality assurance unit functioned as the liaison between inspectors and other members of organization. The inspecting team wrote an observational report based on the audit in the format of FDA Form 483. The instructor coached student teams to write Form 483. An example Form 483 is given in Appendix 4. Every team was inspected once and got a chance to inspect other teams at least once.

\section{Safety compliance module}

Safety and regulatory compliance are conjoined concepts - violation in one can have consequence in the other. Hence, it's logical to offer a SC module in tandem with a RC module. Students in chemical engineering and related disciples are exposed to safety issues routinely in teaching or research labs, and in machine shop environments. Safety has become the new normal in chemical engineering education and gets tremendous emphasis from ABET and AIChE. Several chemical engineering organizations (including AIChE, IChemE, SAChE, and ECCE) and commercial organizations have instituted educational programs such as workshops, hands-on modules, and online learning modules for safety ${ }^{13}$. The module we developed will use some of these materials.

Safety is intuitive, though in the complex situation of a chemical or biochemical process guidelines for safety compliance should to be clearly laid out. Despite the increasing focus on process and lab safety, incidents such as T2 laboratories reactor explosion, sugar plant explosion in Georgia, and alumina sludge spill in Hungary have underscored the importance of adherence to safety regulations and the need for personnel who understand and appreciate process safety. Several niche areas in chemical engineering such as biotechnology and semiconductor industries are advancing faster than the current safety regulations can catch up. A New York Times article in 2010 compiled several lab incidents where current Occupational Safety and Health Administration (OSHA) regulations lag behind technological development in the biotechnology industry $^{14}$. Nevertheless, OSHA guidelines play a very large role in keeping the chemical and related industries safe.

\section{Purpose of the SC module}

The SC module broadly intends to cover both education aspects (i.e., teaching basic concepts and principles underlying safety) and training aspects (i.e., performing a task compliant to regulations and methods of response to safety events). Students are exposed to the jargon and practice of safety compliance. Specifically, this module intends to meet some of the Safety and Chemical Engineering Education (SAChE) recommendations for safety training in chemical engineering ${ }^{15}$.

Major accidents in the chemical industry such as Bhopal isocyanides leak, BP/Transocean oil spill, and sugar refinery explosion in Georgia have been dissected, analyzed 
and valuable lessons have been learnt. However, reports of several unsafe conditions or near miss accidents get much less attention. In the chemical industry, the chance of a near-miss escalating into a major incident is about one in six hundred, and almost every major accident has had a prior history of near misses ${ }^{16}$. Mistakes do happen, but escalation to a major event can be prevented by conscientious employees who are aware of the consequences and have the ability to respond appropriately. The SC module described here will educate students on the basic principles of safety, train them to identify hazards and, to develop mitigation plans.

\section{Topics covered in the SC module}

The SC module is designed to be implemented in laboratory, lecture, or design courses. All SC documentation can be developed through classroom instruction. A quick walk-through of a functioning lab or a plant visit will be useful. Topics covered include:

1. Basic safety calculations

2. Safety regulations in laboratory environments

3. Hazard mapping and materials handling

4. Risk abatement.

\section{$\underline{\text { Safety compliance instruction }}$}

When implementing the SC module, a teaching or research laboratory was used as model. The module started with a brief lecture on safety regulations, history of accidents in chemical and related industries and some practice problems related to safety. An example practice problem is shown in table 3. Practice problems were related to topics in fluid mechanics, mass transfer and kinetics. These problems were assigned as homework.

Table 3. Example problem for safety calculations.

\footnotetext{
The village of Crestwood, IL a southern suburb of Chicago has been in the news for sometime due to its perchlorothylene (PCE) contaminated soil. PCE, a solvent used in dry cleaning is linked to cancer, liver damage and neurological problems. Crestwood relies on wells to supply water to its residents. Water table is at a depth of 2000 feet. Estimate the amount of PEC (in grams) transported to the water table over a period of one month if a $50 \mathrm{~m}^{2}$ surface area of soil is contaminated. Surface concentration of PCE is $2 \mathrm{~g} / \mathrm{m}^{3}$ of soil. Diffusivity of PCE in soil is $8.8 \times 10^{-8} \mathrm{~m}^{2} / \mathrm{s}$.
}

Student teams were asked to develop an emergency management plan for a lab (teaching or research lab) in the department. They were asked to do a walk-around of the space and determine the locations of nearest eye wash, safety shower, first aid kits, and spill kits. They were also asked to identify emergency exit routes, rally points, and emergency contact information for that space. Students used the lab space floor plan to mark the location of safety devices and kits, and to chart emergency routes. Example of an emergency management plan is given in figure 5. Student teams then compared their emergency plan with the universityapproved emergency plan on file. Emergency management plans were also critiqued by the other teams. However, during an emergency the University's plan will supersede any student plans. 


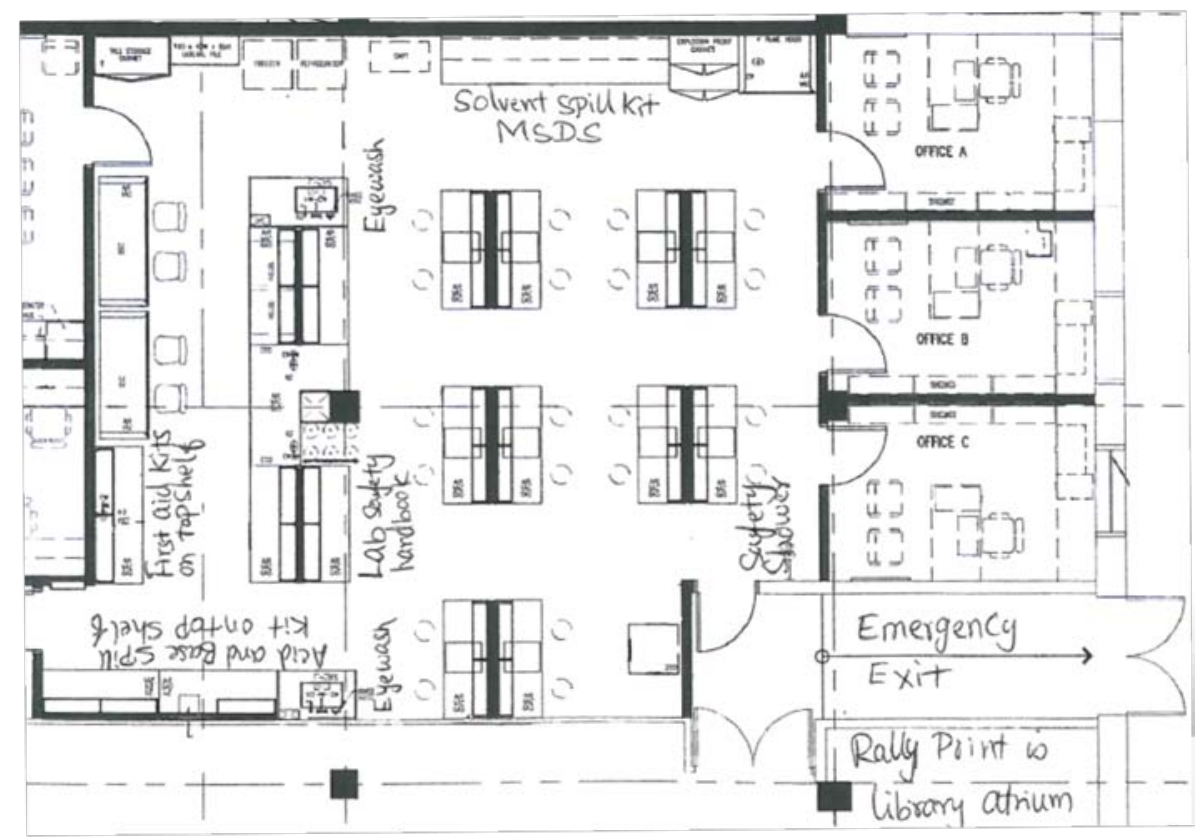

Figure 5. Example emergency management floor plan.

Student teams next developed a protective gear plan for the workspace and for a given experiment. Example experiments are given in table 2. The plan would consider hazards from to materials (chemicals, reagents, sharps such as needles and broken glass, and biological agents), equipments (high pressure, high and low temperatures, high velocity flow systems, moving objects), and infrastructure (electrical cables, steam lines, possibility of falling objects). Students created a list of protective gear required for the space through a brief brainstorm session. OSHA and university's safety guidelines were used for this purpose.

Table 4. Example protective gear plan developed by students.

\begin{tabular}{|l|l|l|}
\hline Protective gear & Protection against & To be used when \\
\hline Lab coats & General chemicals, spills, splashes & Always \\
\hline Goggles & General chemicals, spills, splashes & Always \\
\hline Latex/nitrile gloves & General chemicals, spills, splashes & Always \\
\hline Flame resistant lab coats & Open flame, flammable chemicals & Using the Bunsen burner or solvents \\
\hline Heat resistance gloves & Heat & Using the autoclave \\
\hline Puncture resistant gloves & Sharps & $\begin{array}{l}\text { When using hypodermic needles for injections } \\
\text { or sampling, and when collecting broken glass }\end{array}$ \\
\hline
\end{tabular}

A hazard mapping exercise was performed next. A hazard can impact the immediate user or the building or the general population, both short and long term. Students generated a list of all materials and equipments required for a particular experiment and the hazards associated with them. MSDS and manufacturer's manuals were used to identify hazards. Students also surveyed the internet for any reported hazard events involving the materials and equipments they intend to use. Hazard maps were then developed to identify and locate hazard in specific work areas. A 
hazard map is a visual representation of major hazards in the work area and helps the user to identify them at a glance ${ }^{17}$. We used color and number coded labels to identify hazards ${ }^{18}$. A hazard map of the lab was developed using codes and labels described in table 5. An example hazard map is given in figure 6 .

Table 5. Codes and levels for hazard mapping. Adapted from ref \# 18.

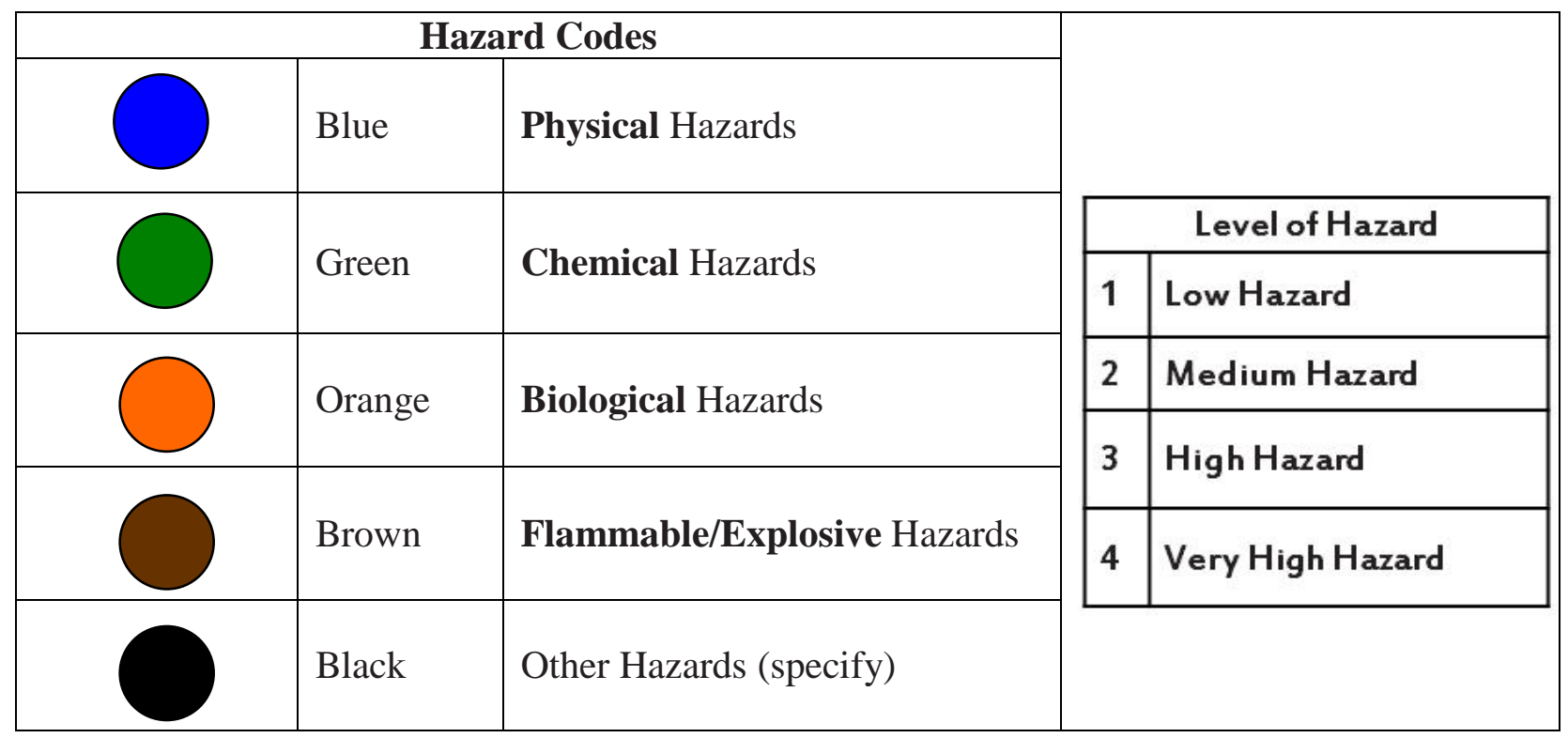

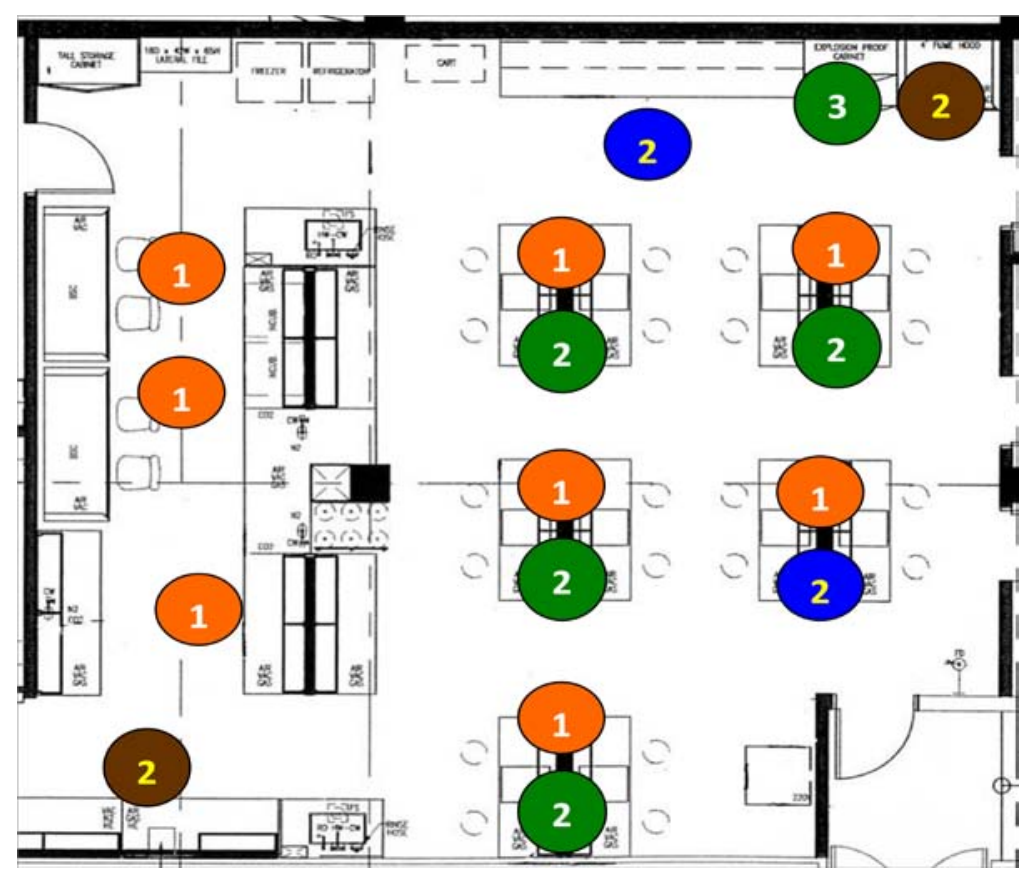

Figure 6. Example hazard map. For the purpose of clarity not all hazards are mapped. See table 5 for hazard codes and levels. 
This exercise was followed by the development of a hazard mitigation (also called risk abatement) plan. Of course, the best hazard management is to eliminate all hazards, which is not realistically possible. The first effort was substitution with a less hazardous material where possible (such as replacing a carcinogenic protein stain with a non-carcinogen, or replacing acid catalyst with a metal catalyst). The next effort was to develop a plan to manage non-removable or non-substitutable risks. This plan had both passive and active mitigation plans. Passive hazard mitigation involves minimal immediate intervention such as a container break, but content captured in a secondary container or a part breaks but the equipment shuts down automatically. Active mitigation requires immediate attention such as a chemical spill. Passive and active hazard mitigation plans were developed for all equipment and chemicals to be used in a particular experiment.

\section{Student opinions on RC and SC module}

Data available on student opinions of the RC and SC modules is anecdotal at this point. All student comments are in free style format as a part of their comments on the course in which these modules were offered. About a third of the comments received were ambiguous as to the usefulness of the RC and SC modules. About $40 \%$ said they liked the module, but many suggested that it was too much work, and about $25 \%$ said they don't see an immediate value in these modules. A good majority (about 90\%) said they enjoyed the role-play exercises but a good number of them (about 70\%) said the documentation part of the modules were onerous.

\section{Recommendations and future directions}

Student comments suggest a mixed bag of opinions, which is to be expected. RC and SC modules tend to standardize thoughts while university education promotes free thinking. Also rote documentation practices based on templates can lead to a bored indifference. But this is how compliance documentation is written in real-life situations. It is important that the students understand this fact. A few suggested future improvements are:

1. Develop a rubric to remove the subjectivity in grading RC and SC modules.

2. Develop methods to make compliance documentation interactive and interesting.

3. Adapt and use RC and SC modules in other courses.

4. Develop methods and obtain quantifiable assessments of learning outcomes and use it for future improvements. 


\section{References}

1. Educating the Engineer of 2020: Adapting Engineering Education to the New Century, National Academies Press (2005).

https://secure.hosting.vt.edu/www.enge.vt.edu/secure/Educating the Engineer of 2020 all.pdf. Last accessed March 26, 2013.

2. Black, K. M. An Industry View of Engineering Education, J. Eng. Ed., 83, 26-28 (1994).

3. Tenenberg, J. Industry Fellows: Bringing Professional Practice into the Classroom, Proceedings of the 41st ACM/SIGCSE Technical Symposium on Computer Science Education, Milwaukee, WI (2010).

4. Lamancusa, J. S., Zayas, J. L., Soyter, A. L., Morell, L., and Jorgensen, J. The learning Factory: Industry-partnered Active Learning, J. Eng. Ed., 97, 5-11 (2008).

5. Atman, C., et al., Enabling Engineering Student Success: The Final Report for the Center for Advancement of Engineering Education. http://www.engr.washington.edu/caee/CAEE\%20final\%20report\%2020101102.pdf. Last accessed March 26, 2013.

6. Knapp, R. Collective (Team) Learning Process Models: A Conceptual Review. Human Resource Development Review, 9, 285-299 (2010).

7. Ohri, A. J., and Olds, B. M. Situated Engineering Learning: Bridging Engineering Education Research and the Learning Sciences, J. Eng. Ed., 100, 151-185 (2011).

8. Survey: How Leading Firms Manage Regulatory Change, Chemical Week Magazine, Nov. 2 (2009).

9. Regulatory Compliance Predicted to be a Major Driver of Competitive Advantage. http://www.prnewswire.com/news-releases/regulatory-compliance-predicted-to-be-a-major-driver-ofcompetitive-advantage-69070552.html. Last accessed March 26, 2013.

10. AIChE ${ }_{100}$ : A Century of Achievement-Vision for the Future: 1908-2008, Chapter 25. http://www.aiche.org/uploadedFiles/About/Centennial/Books/100/AIChE_A Century of Achieveme nts_Chap25.pdf. Last accessed March 26, 2013.

11. Presidential Memoranda - Regulatory compliance, http://www.whitehouse.gov/the-pressoffice/2011/01/18/presidential-memoranda-regulatory-compliance. Last accessed March 26, 2013.

12. Felse, P. A. Regulatory Compliance Training in Bio/Chemical Engineering Courses, Proceedings of the $119^{\text {th }}$ ASEE Annual conference, San Antonio, TX (2012)

13. Pitt, M. J. Teaching Safety in Chemical Engineering, Chem. Eng. Technol. 35, 1341-1345 (2012).

14. Pollack, A., and Wilson, D. Safety Rules Can't Keep Up With Biotech Industry, New York Times (2010). http://www.nytimes.com/2010/05/28/business/28hazard.html?pagewanted=all\&_r=0. Last accessed March 26, 2013.

15. SAChE Recommendations for ABET Safety Content in Chemical Engineering.(2010) http://www.sache.org/SACHEGuidelinesForABET.pdf. Last accessed March 26, 2013.

16. Phimister, J. R., Oktem, U., Kleindorfer, P. R., and Kunreuther, H. Near-Miss Incident Management in the Chemical Process Industry. Risk Analysis, 23, 445-456 (2003)

17. Anderson, J., Collins, M., Devlin, J., Renner, P. Using Hazard Maps to Identify and Eliminate Workplace Heath Hazards: A Union-led Health and Safety Training Program. New Solutions, 22, 325-342 (2012).

18. Preventing Chemical Accidents: Hazard Mapping, Process Safety Management Training from the NJ Work Environment Council, $1^{\text {st }}$ Edn. (2011). 


\section{Appendix 1. GLP guidelines from FDA’s 21 CFR Part 58 relevant to the RC module}

\section{Subpart C--Facilities}

Sec. 58.41 General.

Each testing facility shall be of suitable size and construction to facilitate the proper conduct of nonclinical laboratory studies. It shall be designed so that there is a degree of separation that will prevent any function or activity from having an adverse effect on the study.

[52 FR 33780, Sept. 4, 1987]

Sec. 58.49 Laboratory operation areas.

Separate laboratory space shall be provided, as needed, for the performance of the routine and specialized procedures required by nonclinical laboratory studies.

[52 FR 33780, Sept. 4, 1987]

Sec. 58.51 Specimen and data storage facilities.

Space shall be provided for archives, limited to access by authorized personnel only, for the storage and retrieval of all raw data and specimens from completed studies.

\section{Subpart G--Protocol for and Conduct of a Nonclinical Laboratory Study (leads to SOP)}

Sec. 58.120 Protocol.

(a) Each study shall have an approved written protocol that clearly indicates the objectives and all methods for the conduct of the study. The protocol shall contain, as applicable, the following information:

(1) A descriptive title and statement of the purpose of the study.

(2) Identification of the test and control articles by name, chemical abstract number, or code number.

(3) The name of the sponsor and the name and address of the testing facility at which the study is being conducted.

(4) The number, body weight range, sex, source of supply, species, strain, substrain, and age of the test system.

(5) The procedure for identification of the test system.

(6) A description of the experimental design, including the methods for the control of bias.

(7) A description and/or identification of the diet used in the study as well as solvents, emulsifiers, and/or other materials used to solubilize or suspend the test or control articles before mixing with the carrier. The description shall include specifications for acceptable levels of contaminants that are reasonably expected to be present in the dietary materials and are known to be capable of interfering with the purpose or conduct of the study if present at 
levels greater than established by the specifications.

(8) Each dosage level, expressed in milligrams per kilogram of body weight or other appropriate units, of the test or control article to be administered and the method and frequency of administration.

(9) The type and frequency of tests, analyses, and measurements to be made.

(10) The records to be maintained.

(11) The date of approval of the protocol by the sponsor and the dated signature of the study director.

(12) A statement of the proposed statistical methods to be used.

(b) All changes in or revisions of an approved protocol and the reasons therefore shall be documented, signed by the study director, dated, and maintained with the protocol.

[43 FR 60013, Dec. 22, 1978, as amended at 52 FR 33781, Sept. 4, 1987; 67 FR 9585, Mar. 4, 2002]

\section{Sec. 58.33 Study director.}

For each nonclinical laboratory study, a scientist or other professional of appropriate education, training, and experience, or combination thereof, shall be identified as the study director. The study director has overall responsibility for the technical conduct of the study, as well as for the interpretation, analysis, documentation and reporting of results, and represents the single point of study control. The study director shall assure that:

(a) The protocol, including any change, is approved as provided by 58.120 and is followed.

(b) All experimental data, including observations of unanticipated responses of the test system are accurately recorded and verified.

(c) Unforeseen circumstances that may affect the quality and integrity of the nonclinical laboratory study are noted when they occur, and corrective action is taken and documented.

(d) Test systems are as specified in the protocol.

(e) All applicable good laboratory practice regulations are followed.

(f) All raw data, documentation, protocols, specimens, and final reports are transferred to the archives during or at the close of the study.

[43 FR 60013, Dec. 22, 1978; 44 FR 17657, Mar. 23, 1979] 


\section{Sec. 58.35 Quality assurance unit.}

(a) A testing facility shall have a quality assurance unit which shall be responsible for monitoring each study to assure management that the facilities, equipment, personnel, methods, practices, records, and controls are in conformance with the regulations in this part. For any given study, the quality assurance unit shall be entirely separate from and independent of the personnel engaged in the direction and conduct of that study.

(b) The quality assurance unit shall:

(1) Maintain a copy of a master schedule sheet of all nonclinical laboratory studies conducted at the testing facility indexed by test article and containing the test system, nature of study, date study was initiated, current status of each study, identity of the sponsor, and name of the study director.

(2) Maintain copies of all protocols pertaining to all nonclinical laboratory studies for which the unit is responsible.

(3) Inspect each nonclinical laboratory study at intervals adequate to assure the integrity of the study and maintain written and properly signed records of each periodic inspection showing the date of the inspection, the study inspected, the phase or segment of the study inspected, the person performing the inspection, findings and problems, action recommended and taken to resolve existing problems, and any scheduled date for reinspection. Any problems found during the course of an inspection which are likely to affect study integrity shall be brought to the attention of the study director and management immediately.

(4) Periodically submit to management and the study director written status reports on each study, noting any problems and the corrective actions taken.

(5) Determine that no deviations from approved protocols or standard operating procedures were made without proper authorization and documentation.

(6) Review the final study report to assure that such report accurately describes the methods and standard operating procedures, and that the reported results accurately reflect the raw data of the nonclinical laboratory study.

(7) Prepare and sign a statement to be included with the final study report which shall specify the dates inspections were made and findings reported to management and to the study director.

(c) The responsibilities and procedures applicable to the quality assurance unit, the records maintained by the quality assurance unit, and the method of indexing such records shall be in writing and shall be maintained. These items including inspection dates, the study inspected, the phase or segment of the study inspected, and the name of the individual performing the inspection shall be made available for inspection to authorized employees of the Food and Drug Administration.

(d) A designated representative of the Food and Drug Administration shall have access to the written procedures established for the inspection and may request testing facility management to certify that inspections are being implemented, performed, documented, and followed-up in accordance with this paragraph.

[43 FR 60013, Dec. 22, 1978, as amended at 52 FR 33780, Sept. 4, 1987; 67 FR 9585, Mar. 4, 2002] 


\section{Appendix 2. Example SOP template.}

\begin{tabular}{|l|l|}
\hline & Preparation of standard curve (or other title) \\
\cline { 2 - 2 } & Procedure \#: SOP-xxx \\
\hline
\end{tabular}

$\underline{\text { Studv Sponsor: }}$

$\underline{\text { Summary }}$

1.1. Purpose (what is this procedure for? what is the use of data generated from this procedure? procedure notes such as range, scale-up, special notes, if any)

1.2. Scope (to whom and where does this procedure apply?)

1.3. Responsibility (who is responsible for the proper conduct of this experiment - title such as lab manager, study director, etc.?)

1. Materials

1.1. Equipments needed:
\begin{tabular}{|l|l|}
\hline Equipment & Nake \\
\hline Balance & \\
\hline $1000 \mu L$ pipetman & \\
\hline & \\
\hline & \\
\hline
\end{tabular}

1.2. Supplies needed:

\begin{tabular}{|l|l|l|}
\hline Item & Vendor & Catalog \# \\
\hline $15 \mathrm{~mL}$ centrifuge tubes & & \\
\hline $5 \mathrm{~mL}$ pipettes & & \\
\hline & & \\
\hline & & \\
\hline & & \\
\hline
\end{tabular}

1.3. Reagents and chemicals needed:

\begin{tabular}{|l|l|l|}
\hline Chemicals/reagents & Vendor & Catalog \# \\
\hline $15 \mathrm{~mL}$ centrifuge tubes & & \\
\hline $5 \mathrm{~mL}$ pipettes & & \\
\hline & & \\
\hline & & \\
\hline & & \\
\hline
\end{tabular}

1.4. Reagent preparation

1.4.1. Preparation of stock $(50 \mathrm{mg} / \mathrm{mL})$

1.4.2.

2. Procedure (include tables if needed. acquire all

1.1. Preparation of dilutions

1.2. Preparation of blank

1.3

14

3. Results reporting (format for reporting data in tabular, fill-in-the-blank, or other form: include information on replicates necessary)

1.1. OD data

1.2. Standard curve

13

4. Errors and acceptable range (only instrument errors and their range)

5. Procedure notes

6. Records to be maintained

1.1. SOP

1.1.1. Store in (place, identification, and location)

1.1.2. Log information in (place, identification, and location) 1.2. Batch record

1.2.1.

1.2.2.

1.3. Lab notebooks

1.3.1.

1.3.2.

1.4

1.5

7. References (include references if any)

7.1

7.2

7.3

8. Approval
1.1. Generated by:
Date:
Signature:
1.2. Accepted by
Date:
Signature:
1.3. Approved by
Date:
Signature:

10. Change history (you will not do this in the lab course)

10.1. First revision

10.1.1. Change:

10.1.2. Reason for the change:

10.1.3. Generated by:

Date:

Signature:

10.1.4. Accepted by:

Date:

Signature:

10.1.5. Approved by:

Date:

Signature: 
Appendix 3. Example batch record template.

\begin{tabular}{|l|l|}
\hline \multicolumn{2}{|l}{ Experiment Batch Record } \\
\hline Document t: & Order H: \\
\hline
\end{tabular}

\section{BATCH RECORD ISSUANCE}

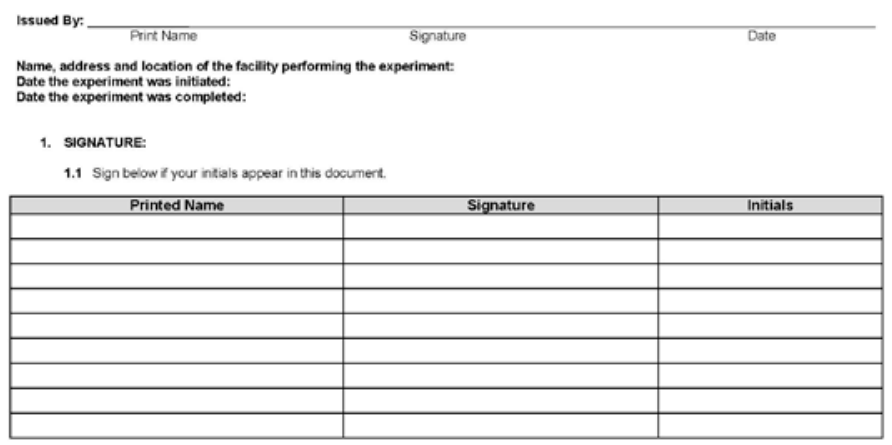

\begin{tabular}{|c|c|c|c|c|c|c|}
\hline & & & & & \multicolumn{2}{|c|}{ Experiment Batch Record } \\
\hline Document + : & & & \multicolumn{2}{|l|}{ Order \#: } & & \\
\hline \multicolumn{7}{|c|}{ Ttile: Generating a standard curve } \\
\hline \multicolumn{7}{|l|}{ 5. EQUIPMENT: } \\
\hline Equipment Name & Make/model & $\begin{array}{l}\text { Serial or ID } \\
\text { Number }\end{array}$ & $\begin{array}{l}\text { Calibration/mai } \\
\text { ntenance Due } \\
\text { Date }\end{array}$ & $\begin{array}{l}\text { Calibration/ } \\
\text { maintenance } \\
\text { done by/Date }\end{array}$ & $\begin{array}{c}\text { Calibration/maint } \\
\text { enance verified } \\
\text { by/Date }\end{array}$ & \begin{tabular}{|c|} 
Person \\
responsible for \\
the instrument
\end{tabular} \\
\hline \multicolumn{7}{|l|}{ Spectrophotometer } \\
\hline & & & & & & \\
\hline & & & & & & \\
\hline & & & & & & \\
\hline & & & & & & \\
\hline
\end{tabular}

6. SOFTWARE AND STATISTICAL TOOLS:
\begin{tabular}{|l|l|l|l|l|l|l|}
\hline Software Name & Vendor/version & $\begin{array}{c}\text { ID Number, if } \\
\text { any }\end{array}$ & $\begin{array}{c}\text { Validation due } \\
\text { Date }\end{array}$ & $\begin{array}{c}\text { Validation } \\
\text { done by/Date }\end{array}$ & $\begin{array}{c}\text { Validation } \\
\text { verified by/Date }\end{array}$ & $\begin{array}{c}\text { Person } \\
\text { responsible for } \\
\text { the software }\end{array}$ \\
\hline Excel & & & & & & \\
\hline & & & & & & \\
\hline & & & & & & \\
\hline & & & & & & \\
\hline & & & & & & \\
\hline
\end{tabular}

\begin{tabular}{|c|c|c|c|c|}
\hline & & & ent Batch F & Record \\
\hline Docume & & Order \#: & & \\
\hline Title: $\mathrm{G}$ & rating a standard cur & & & \\
\hline Step \# & Operational Description & Data Entry & \begin{tabular}{|c|} 
Performed \\
by/Date
\end{tabular} & $\begin{array}{l}\text { Verified } \\
\text { by/Date }\end{array}$ \\
\hline 7.2 & Preparation of blank & & & \\
\hline 7.21 & & & & \\
\hline 7.2 .2 & & & & \\
\hline 7.2 .3 & & & & \\
\hline 7.3 & Measurement of samples & & & \\
\hline 7.3 .1 & & & & \\
\hline 7.3 .2 & & & & \\
\hline 7.3 .3 & & & & \\
\hline
\end{tabular}

\begin{tabular}{|l|l|}
\hline \multicolumn{2}{|l|}{ Experiment Batch Record } \\
\hline Document \#: & Order \#: \\
\hline Titele: Generating a standard curve & \\
\hline
\end{tabular}
\begin{tabular}{|l|l|}
\hline 2 REFERENCES: & Title \\
\hline SOP number & \\
\hline
\end{tabular}

3. LIST OF SUPPLIES:
\begin{tabular}{|c|c|c|c|c|c|}
\hline Item Description & Vendor & Catalog \# & Lot \# & Date opened & $\begin{array}{c}\text { Quantity } \\
\text { required }\end{array}$ \\
\hline $15 \mathrm{~mL}$ Polypropylene Concal tubes & & & & & \\
\hline & & & & & \\
\hline & & & & & \\
\hline & & & & & \\
\hline & & & & & \\
\hline
\end{tabular}

4. REAGENTS AND CHEMCIALS:

\begin{tabular}{|c|l|l|l|l|l|l|l|}
\hline Material Description & Vendor & Catalog\# & Lot \# & $\begin{array}{c}\text { Storage } \\
\text { Condition }\end{array}$ & $\begin{array}{c}\text { Date } \\
\text { opended }\end{array}$ & $\begin{array}{c}\text { Quantity } \\
\text { Required }\end{array}$ & $\begin{array}{c}\text { Verified By } \\
\text { (TA signatures) }\end{array}$ \\
\hline & & & & & & & \\
\hline & & & & & & & \\
\hline & & & & & & & \\
\hline & & & & & & & \\
\hline & & & & & & & \\
\hline
\end{tabular}

\begin{tabular}{|l|l|}
\hline \multicolumn{2}{|l|}{ Experiment Batch Record } \\
\hline Document \#: & Order \#: \\
\hline Title: Generating a standard curve & \\
\hline
\end{tabular}

7. PROCEDURE:

\begin{tabular}{|c|c|c|c|c|}
\hline Step \# & Operational Description & Data Ent & \begin{tabular}{|c|}
$\begin{array}{c}\text { Performed } \\
\text { by/Date }\end{array}$ \\
\end{tabular} & \begin{tabular}{|l} 
Verified \\
by/Date
\end{tabular} \\
\hline 7.1 & Preparation of dilutions & & & \\
\hline \multirow{2}{*}{7.1 .1} & \multirow{2}{*}{ Dilution \#1 } & Dilution \#1 Date & & \\
\hline & & Dilution \#1 Time & & \\
\hline \multirow{2}{*}{7.1 .2} & \multirow{2}{*}{ Dilution \#2 } & Dilution \#2 Date & & \\
\hline & & Dilution \#2 Time & & \\
\hline 7.1 .3 & & & & \\
\hline & & & & \\
\hline 7.1 .4 & & & & \\
\hline
\end{tabular}

\begin{tabular}{|l|l|}
\hline \multicolumn{2}{|c|}{ Experiment Batch Record } \\
\hline Document \#: & Order \#: \\
\hline Title: Generating a standard curve & \\
\hline
\end{tabular}

8. COMMENTS: (INCLUDE STEP NUMBER REFERENCE)

9. EXPERIMENT REVIEW BY:

Signature: Date: Printed Name:

$$
\begin{aligned}
& \text { 这 } \\
& \text { N } \\
& \omega \\
& \text { ले } \\
& \overrightarrow{0}
\end{aligned}
$$


Appendix 4. Example Form 483.

\section{DEPARTMENT OF HEALTH AND HUMAN SERVICES \\ FOOD AND DRUG ADMINISTRATION \\ FORM 483}

\section{DATE OF INSPECTION}

$05 / 15 / 2012$

\section{NAME AND TITLE OF INDIVIDUAL TO WHOM REPORT IS ISSUED \\ TO: Study Director \\ COMPANY NAME \\ University}

\section{STREET ADDRESS}

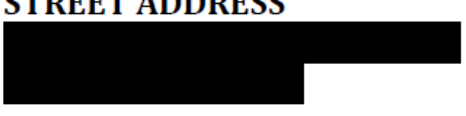

CITY, STATE AND ZIP CODE

TYPE OF ESTABLISHMENT INSPECTED

Bioprocess Engineering Teaching Laboratory

\section{DURING AN INSPECTION OF YOUR FACILITY WE OBSERVED:}

1. Proper waste disposal and cleaning procedures were not established. There was unidentified liquid solution present in the ultrafiltration equipment that was used for conducting experiment.

2. Batch record was not approved by a second authority and the QA unit.

3. Batch record was incomplete and had missing information. A complete list of supplies was not provided - pipettor, pipet tips etc.

4. Information in batch record was not organized and recorded correctly in appropriate sections. Pipette tips were included as reagent and not supplies.

5. Inaccurate/incomplete information was provided in batch records.

a. A solution was albumin $(2.5 \mathrm{mg} / \mathrm{mL} \mathrm{BSA})$ was used as a reagent for the experiment.

However, albumin powder was mentioned in the list of reagents used

b. Certain words, such as Drawer, were misspelled.

6. Experimental limitations were not clearly understood - the study director confirmed that there is no rationale to make inferences based on the value of $\mathrm{R}^{2}$.

\begin{tabular}{|l|l|l|}
\hline Investigator signature & Investigator name & Date issued \\
& & $05 / 16 / 2012$ \\
\hline
\end{tabular}

